\title{
ON THE STARK BROADENING OF RU III SPECTRAL LINES
}

\author{
MILAN S. DIMITRIJEVIĆ ${ }^{1,2, \star}$ \\ ${ }^{1}$ Astronomical Observatory, Volgina 7, 11060 Belgrade, Serbia \\ ${ }^{2}$ Sorbonne Université, Observatoire de Paris, Université PSL, CNRS, LERMA, F-92190, Meudon, France
}

\begin{abstract}
Stark broadening parameters, full widths at half maximum (FWHM) and shifts for spectral lines within six multiplets of doubly charged ruthenium ions have been calculated, for an electron density of $10^{17} \mathrm{~cm}^{-3}$ and temperature range from $10000 \mathrm{~K}$ to $160000 \mathrm{~K}$. Calculations have been performed with the simplified modified semiempirical (SMSE) approach. In the case of two multiplets, it is possible to apply the full modified semiempirical method. The corresponding calculations have been performed and results are compared in order to test and determine the accuracy of the SMSE approach. The results are also used for the consideration of Stark width and shift regularities in Ru III spectrum.
\end{abstract}

Keywords: Stark broadening, Spectral lines, Line profiles, Ru III.

\section{INTRODUCTION}

Spectral line profiles in spectra emitted from various plasmas are very useful and precious source of informations about plasma conditions, like electron density, temperature and chemical composition. Among different line broadening mechanisms, Stark broadening due to interaction of emitter/absorber with surrounding charged particles has many useful applications in astrophysics (see e.g. Dimitrijević (2017)), as well as for laboratory plasmas investigation and especially diagnostics. Stark broadening data are also useful for different investigations and modelling of fusion plasma, laser produced plasma diagnostic and analysis, as well as for its different applications in industry and technology as for example for welding, melting and piercing of metals by laser produced plasmas (see for example Dimitrijević (2017) and references therein). Such data are also needed for design and development of light sources using different plasmas (Dimitrijević \& Sahal-Bréchot, 2014), as well as for development of laser devices.

One of trace elements, which importance for stellar physics increases with the development of spectroscopic possibilities to obtain high resolution spectra using instruments on board of satellites and on large terrestrial telescopes is ruthenium, a transition metal belonging to the platinum group of the periodic table. In industry and technology, ruthenium is used for wear-resistant electrical contacts and thick-film resistors, as well as in platinum alloys and as a chemistry catalyst.

It is created in stellar interiors in r-process (rapid neutron capture) and it is present in stellar plasma. Yet Merril (1947) found ruthenium lines in the spectrum of $\mathrm{R}$ Andromedae. Adelman et al. (1979) found that Ru I spectral lines are possibly present in gama Equulei (HD 201601), an Ap star where Stark broadening might be of interest. Biémont et al. (1984) determined that solar abundance of ruthenium is 1.84 . With the development of space astronomy and large telescopes of new generation, number of stars where ruthenium is found increased. So Allen \& Porto de Mello (2007) determined Ruthenium abundances in a large sample of giant and dwarf barium stars, within a wide range of plasma parameters. The effective temperatures were $4300 \mathrm{~K}<T_{\text {eff }}<6500 \mathrm{~K}$ and logarithm of surface gravity $1.4 \leq \log g<4$.6. We note that for largest surface gravities and effective temperatures in this sample Stark broadening might be of interest. Roederer et al. (2010) found Ru I lines in the optical spectrum of r-process enriched metal-poor star BD +173248 , obtained with the High Resolution Echelle Spectrograph on Keck telescope. Hansen et al. (2014) performed a large consistent study of ruthenium abundances in our Galaxy, using a sample of 52 stars with Ru I lines in their spectra. They underlined that ruthenium is important for nucleosynthetic diagnostics. Mishenina et al. (2019) found Ru I spectral lines and determined ruthenium abundance for a sample of $162 \mathrm{~F}-, \mathrm{G}-$, and K-stars belonging to different substructures of the Milky Way.

We can see that ruthenium is widely present in stellar plasma and the corresponding Stark broadening data are needed for determination of abundances, radiative transfer calculations, stellar opacity calculations, modelling of stellar atmospheres and stellar spectra analysis and synthesis. Such data are particularly needed for white dwarfs, where the condition for Stark broadening are very favorable so that it is the principal pressure broadening mechanism (Beauchamp et al., 1997; Tankosić et al., 2003; Milovanović et al., 2004; Simić et al., 2006). Stark broadening is often non negligible and in the case of A type and late B type stars (see for example Simić et al. (2005b,a, 2009)).

In spite of its wide presence in stellar plasma, the corresponding atomic data, needed for various problems in astrophysics and physics are scarce and neither experimental nor theoretical data on Stark broadening exist in literature. In order to provide some of the needed data we calculated here Stark full widths at half maximum (FWHM - W) and shifts the for six multiplets in

\footnotetext{
${ }^{\star}$ Corresponding author: mdimitrijevic@aob.rs
} 
the spectrum of doubly charged ruthenium ion by using the simplified modified semiempirical method - SMSE (Dimitrijević \& Konjević, 1987). Additionally, for two multiplets, for which is possible to apply the full modified semiempirical method - MSE (Dimitrijević \& Konjević, 1980; Dimitrijević \& Kršljanin, 1986; Dimitrijević \& Popović, 2001), analyzed in Dimitrijević (2017). The results obtained using both methods are compared in order to test the accuracy of SMSE method. The obtained results are also used for discussion of regularities of Stark broadening parameters. The obtained results for Ru III will be included in the STARK-B (Sahal-Bréchot et al., 2015; Sahal-Bréchot et al., 2020) database.

\section{NOTES ON CALCULATIONS}

$\mathrm{Ru}$ III has atomic number 44 and belongs to the isoelectronic sequence of molybdenum. Atomic energy levels needed for the corresponding calculations have been taken from Kramida et al. (2020) and Moore (1971). The existing data for atomic energy levels are scarce and not complete. Consequently, it is not possible to use in appropriate way the more accurate semiclassical perturbation method (Sahal-Bréchot, 1969a,b; Sahal-Bréchot et al., 2014).

The modified semiempirical method (MSE) (Dimitrijević \& Konjević, 1980; Dimitrijević \& Kršljanin, 1986; Dimitrijević \& Popović, 2001) is applicable only for two multiplets, for which we performed calculations of full width at half intensity maximum (FWHM) W. Since this method is presented recently in Dimitrijević (2017), we will not repeat this here.

For other four multiplets the simplified modified semiempirical (SMSE) method (Dimitrijević \& Konjević, 1987) is the most advanced method that is applicable in an adequate way, without $a b$ initio calculations when one first calculates the needed atomic energy levels. This method is applied to all six Ru III multiplets considered here. It is well described recently (Dimitrijević, 2020), so there is no need to describe it again.

For the case of the six Ru III multiplets we checked the validity condition of SMSE method (see e.g. Dimitrijević (2020)):

$$
x_{\mathrm{jj}}=E /\left|E_{\mathrm{j}^{\prime}}-E_{\mathrm{j}}\right| \leq 2
$$

Here, $E=3 k T / 2$, is energy of free electron, $\mathrm{j}=\mathrm{i}$,f, where $\mathrm{i}$ is for initial atomic energy level of the considered spectral line and $f$ for final, $E_{\mathrm{j}^{\prime}}\left(\mathrm{j}^{\prime}=\mathrm{i}^{\prime}\right.$ or $\left.\mathrm{f}^{\prime}\right)$ is the nearest atomic energy level for which exists possibility of an allowed dipole transition from or to the energy level i or f. So $X$ is ratio of energy of free electron and of energy difference between initial or final level and the nearest perturbing level. As the validity condition we take the higher $x$ value of values for initial and final levels.

We can calculate one value for the whole multiplet if the so called "one electron approximation" (Griem, 1974) is valid,namely if the energy distance between atomic energy levels in particular terms making the considered multiplet is much lower than the closest energy distance between two considered terms. In such a case we calculate an average energy of the term using the expression:

$$
E=\frac{\sum_{\mathbf{J}}(2 \mathrm{~J}+1) E_{\mathbf{J}}}{\sum_{\mathbf{J}}(2 \mathrm{~J}+1)},
$$

where $E$ is the averaged energy and $E_{\mathrm{J}}$ and $\mathrm{J}$ energy and total angular momentum of a particular energy level.

If we want to obtain Stark broadening parameter, width or shift, for a particular spectral line within the considered multiplet, for the width, for example, we can use the expression:

$$
W_{\text {line }}=\left(\lambda_{\text {line }}^{2} / \lambda_{\text {mult }}^{2}\right) W_{\text {mult }}
$$

where $W_{\text {line }}$ and $\lambda_{\text {line }}$ are width and wavelength of a particular line within multiplet, while $W_{\text {mult }}$ and $\lambda_{\text {mult }}$ are the corresponding values for the multiplet. The equation for the shift is analogous.

\section{RESULTS AND DISCUSSION}

With the help of SMSE approach (Dimitrijević \& Konjević, 1987) we calculated Full Stark widths at half intensity maximum (W) and shifts (d) for six multiplets of doubly charged ruthenium (Ru III) with spectral lines broadened due to collisions with electrons, for an electron density of $10^{17} \mathrm{~cm}^{-3}$ and plasma temperatures of $10000,20000,40000,80000$ and $160000 \mathrm{~K}$. Additionally, for multiplets $5 \mathrm{~s}^{7} \mathrm{~S}-5 \mathrm{p}^{7} \mathrm{P}^{o}$ and $5 \mathrm{~s}^{5} \mathrm{~S}-5 \mathrm{p}^{5} \mathrm{P}^{o}$ we calculated Stark widths using more sophisticated MSE method (Dimitrijević \& Konjević, 1980), since only for those two multiplets application of this method is adequate.

The obtained results for Stark widths (W) and shifts (d) are presented in Table 1. We note that for high densities linear dependence of Stark widths and shifts in function of density of electrons, may be influenced by Debye screening. In the last column the validity condition of the SMSE method, given by Eq. (1) is presented. We can see that for $T=160000 \mathrm{~K}$ validity condition for SMSE method is not satisfied. These values are given for better interpolation for temperatures larger than $80000 \mathrm{~K}$.

If we compare the SMSE width with more sophisticated MSE calculations, we can see that in the case of $5 \mathrm{~s}^{7} \mathrm{~S}-5 \mathrm{p}^{7} \mathrm{P}^{o}$ multiplet at the temperature of $10000 \mathrm{~K}$, SMSE width is $14 \%$ larger than MSE width and for 160000 this difference is only $5.3 \%$. In the case of $5 \mathrm{~s}^{5} \mathrm{~S}-5 \mathrm{p}^{5} \mathrm{P}^{o}$ multiplet, these values are $13.5 \%$ and $1.6 \%$ respectively. First of all this confirms that more approximate SMSE results are acceptable. An interesting result is that for temperature of $160000 \mathrm{~K}$, where validity condition is not satisfied the obtained results are even in better mutual agreement which implies that all results for $T=160000 \mathrm{~K}$ in Table 1 are acceptable.

Besides Stark broadening parameters in $\AA$ units, which is common presentation, in Table 1 they are given and in angular frequency units $(\mathrm{s}-1)$. This is more suitable for discussion of regularities because in such a way the influence of wavelength is avoided. The relation between Stark widths in $\AA$ units and in s-1 units is: 
Table 1. This table gives electron-impact broadening (Stark broadening) Full Widths at Half Intensity Maximum (W) and shifts (d) for $\mathrm{Ru}$ III spectral lines, for a perturber density of $10^{17} \mathrm{~cm}^{-3}$ and temperatures from 10000 to $160000 \mathrm{~K}$. Also, the $3 k T / 2 \Delta E$, quantity is given, where $\Delta E$ is the energy difference between closest perturbing level and the closer of initial and final levels. In order that the used method is valid, this quantity should be less or equal two.

\begin{tabular}{|c|c|c|c|c|c|c|c|}
\hline Transition & $\mathrm{T}(\mathrm{K})$ & $\mathrm{W}[\AA]$ & $\mathrm{d}[\AA]$ & $\mathrm{W}\left[10^{12} \mathrm{~s}^{-1}\right]$ & $\mathrm{d}\left[10^{12} \mathrm{~s}^{-1}\right]$ & $\mathrm{W}_{M S E}[\AA]$ & $3 \mathrm{kT} / 2 \Delta \mathrm{E}$ \\
\hline $\mathrm{Ru}$ III $5 \mathrm{~s}^{7} \mathrm{~S}-5 \mathrm{p}^{7} \mathrm{P}^{o}$ & 10000. & $0.478 \mathrm{E}-01$ & $-0.116 \mathrm{E}-01$ & 0.228 & $-0.553 \mathrm{E}-01$ & $0.419 \mathrm{E}-01$ & 0.207 \\
\hline \multirow[t]{4}{*}{$\lambda=1988.0 \AA$} & 20000. & $0.338 \mathrm{E}-01$ & $-0.821 \mathrm{E}-02$ & 0.161 & $-0.391 \mathrm{E}-01$ & $0.296 \mathrm{E}-01$ & 0.415 \\
\hline & 40000. & $0.239 \mathrm{E}-01$ & $-0.580 \mathrm{E}-02$ & 0.114 & $-0.277 \mathrm{E}-01$ & $0.210 \mathrm{E}-01$ & 0.829 \\
\hline & 80000. & $0.169 \mathrm{E}-01$ & $-0.410 \mathrm{E}-02$ & $0.805 \mathrm{E}-01$ & $-0.196 \mathrm{E}-01$ & $0.148 \mathrm{E}-01$ & 1.66 \\
\hline & 160000. & $0.119 \mathrm{E}-01$ & $-0.290 \mathrm{E}-02$ & $0.569 \mathrm{E}-01$ & $-0.138 \mathrm{E}-01$ & $0.113 \mathrm{E}-01$ & 3.32 \\
\hline Ru III $5 p^{7} \mathrm{P}^{o}-5 d^{7} \mathrm{D}$ & 10000. & $0.495 \mathrm{E}-01$ & $-0.684 \mathrm{E}-02$ & 0.335 & $-0.462 \mathrm{E}-01$ & & 0.207 \\
\hline \multirow[t]{4}{*}{$\lambda=1669.2 \AA$} & 20000. & $0.350 \mathrm{E}-01$ & $-0.484 \mathrm{E}-02$ & 0.237 & $-0.327 \mathrm{E}-01$ & & 0.415 \\
\hline & 40000 . & $0.248 \mathrm{E}-01$ & $-0.342 \mathrm{E}-02$ & 0.167 & $-0.231 \mathrm{E}-01$ & & 0.829 \\
\hline & 80000. & $0.175 \mathrm{E}-01$ & $-0.242 \mathrm{E}-02$ & 0.118 & $-0.164 \mathrm{E}-01$ & & 1.66 \\
\hline & 160000. & $0.124 \mathrm{E}-01$ & $-0.171 E-02$ & $0.837 \mathrm{E}-01$ & $-0.116 \mathrm{E}-01$ & & 3.32 \\
\hline $\mathrm{Ru}$ III $5 \mathrm{p}^{7} \mathrm{P}^{o}-6 \mathrm{~s}^{7} \mathrm{~S}$ & 10000. & 0.102 & $0.422 \mathrm{E}-01$ & 0.690 & 0.286 & & 0.207 \\
\hline \multirow[t]{4}{*}{$\lambda=1666.2 \AA$} & 20000. & $0.719 \mathrm{E}-01$ & $0.298 \mathrm{E}-01$ & 0.488 & 0.202 & & 0.415 \\
\hline & 40000 . & $0.508 \mathrm{E}-01$ & $0.211 \mathrm{E}-01$ & 0.345 & 0.143 & & 0.829 \\
\hline & 80000. & $0.359 \mathrm{E}-01$ & $0.149 \mathrm{E}-01$ & 0.244 & 0.101 & & 1.66 \\
\hline & 160000. & $0.254 \mathrm{E}-01$ & $0.105 \mathrm{E}-01$ & 0.172 & $0.716 \mathrm{E}-01$ & & 3.32 \\
\hline $\mathrm{Ru}$ III $5 \mathrm{~s}^{5} \mathrm{~S}-5 \mathrm{p}^{5} \mathrm{P}^{o}$ & 10000. & $0.747 \mathrm{E}-01$ & $-0.178 \mathrm{E}-01$ & 0.263 & $-0.626 \mathrm{E}-01$ & $0.658 \mathrm{E}-01$ & 0.241 \\
\hline \multirow[t]{4}{*}{$\lambda=2314.1 \AA$} & 20000. & $0.528 \mathrm{E}-01$ & $-0.126 \mathrm{E}-01$ & 0.186 & $-0.443 \mathrm{E}-01$ & $0.465 \mathrm{E}-01$ & 0.483 \\
\hline & 40000. & $0.374 \mathrm{E}-01$ & $-0.890 \mathrm{E}-02$ & 0.131 & $-0.313 \mathrm{E}-01$ & $0.329 \mathrm{E}-01$ & 0.965 \\
\hline & 80000. & $0.264 \mathrm{E}-01$ & $-0.629 \mathrm{E}-02$ & $0.929 \mathrm{E}-01$ & $-0.221 \mathrm{E}-01$ & $0.233 \mathrm{E}-01$ & 1.93 \\
\hline & 160000. & $0.187 \mathrm{E}-01$ & $-0.445 \mathrm{E}-02$ & $0.657 \mathrm{E}-01$ & $-0.156 \mathrm{E}-01$ & $0.184 \mathrm{E}-01$ & 3.86 \\
\hline \multirow{5}{*}{$\begin{array}{c}\mathrm{Ru} \text { III } 5 \mathrm{p}^{5} \mathrm{P}^{o}-5 \mathrm{~d}^{5} \mathrm{D} \\
\lambda=1782.3 \AA\end{array}$} & 10000. & $0.643 \mathrm{E}-01$ & $-0.801 \mathrm{E}-02$ & 0.381 & $-0.475 \mathrm{E}-01$ & & 0.241 \\
\hline & 20000. & $0.454 \mathrm{E}-01$ & $-0.566 \mathrm{E}-02$ & 0.269 & $-0.336 \mathrm{E}-01$ & & 0.483 \\
\hline & 40000. & $0.321 \mathrm{E}-01$ & $-0.400 \mathrm{E}-02$ & 0.191 & $-0.237 \mathrm{E}-01$ & & 0.965 \\
\hline & 80000. & $0.227 \mathrm{E}-01$ & $-0.283 \mathrm{E}-02$ & 0.135 & $-0.168 \mathrm{E}-01$ & & 1.93 \\
\hline & 160000. & $0.161 \mathrm{E}-01$ & $-0.200 \mathrm{E}-02$ & $0.953 \mathrm{E}-01$ & $-0.119 \mathrm{E}-01$ & & 3.86 \\
\hline \multirow{5}{*}{$\begin{array}{c}\mathrm{Ru} \text { III } 5 \mathrm{p}^{5} \mathrm{P}^{o}-6 \mathrm{~s}^{5} \mathrm{~S} \\
\lambda=1806.1 \AA\end{array}$} & 10000. & 0.127 & $0.518 \mathrm{E}-01$ & 0.736 & 0.299 & & 0.241 \\
\hline & 20000 . & $0.901 \mathrm{E}-01$ & $0.366 \mathrm{E}-01$ & 0.521 & 0.212 & & 0.483 \\
\hline & 40000. & $0.637 \mathrm{E}-01$ & $0.259 \mathrm{E}-01$ & 0.368 & 0.150 & & 0.965 \\
\hline & 80000. & $0.451 \mathrm{E}-01$ & $0.183 \mathrm{E}-01$ & 0.260 & 0.106 & & 1.93 \\
\hline & 160000. & $0.319 \mathrm{E}-01$ & $0.130 \mathrm{E}-01$ & 0.184 & $0.748 \mathrm{E}-01$ & & 3.86 \\
\hline
\end{tabular}

$$
W(\AA)=\frac{\lambda^{2}}{2 \pi c} W\left(s^{-1}\right),
$$

where $c$ is the speed of light. The corresponding relation for the shifts is analogous.

It is useful to consider regularities of Stark widths and shifts, since when they exist, we can use this for estimates of the unknown values from the known ones. Wiese \& Konjević (1982) and Wiese \& Konjević (1992) demonstrated that the differences between Stark widths or between shifts, expressed in angular frequency units, are less than $40 \%$ within a transitions array, namely the transition of the type $n \ell-n ' \ell$ ', where $n$ is principal quantum number and $\ell$ orbital angular momentum quantum number. In the case of considered Ru III multiplets, for $5 \mathrm{~s}-5 \mathrm{p}$ transition array the width for septet is $15.4 \%$ larger from the width of quintuplet at $10000 \mathrm{~K}$ and $15.5 \%$ at $160000 \mathrm{~K}$. For the shift these values are
$13.2 \%$ and $13.0 \%$ respectively. For $5 \mathrm{p}-5 \mathrm{~d}$ transition array these values are $13.7 \%$ and $13.9 \%$ for the width as well as $2.81 \%$ and $2.59 \%$ for the shift. In the case of $5 \mathrm{p}-6 \mathrm{~s}$ transition array we have $6.7 \%$ and $6.98 \%$ for the width as well as $4.55 \%$ and $4.47 \%$ for the shift. In all cases these values are well within the limits of $\pm 40 \%$ predicted by Wiese \& Konjević (1982) and Wiese \& Konjević (1992). We can also see that the differences are approximately the same at $10000 \mathrm{~K}$ and $160000 \mathrm{~K}$. These findings can be used for the estimate of missing widths and shifts from the considered transition arrays.

\section{CONCLUSION}

With the help of SMSE theoretical method we have calculated Stark full widths at half intensity maximum and shifts for six $\mathrm{Ru}$ III multiplets. For two of them calculations of the line widths have 
been performed also using more accurate MSE method. Comparison of MSE and SMSE values confirms that SMSE approach gives correct results even for temperatures slightly beyond the domain of validity of SMSE approach. We investigated also regularities of Stark broadening parameters within Ru III transition arrays and found that differences are within the limits of $15.5 \%$, so that calculated values could be used to estimate the missing ones from the considered transition arrays. The Stark broadening parameters for multiplets of doubly charged ruthenium, obtained in this work, will be implemented in the STARK-B database (Sahal-Bréchot et al., 2015; Sahal-Bréchot et al., 2020) which also can be accessed through the portal (http://portal.vamdc.eu) of the European Virtual Atomic and Molecular Data Center - VAMDC (Dubernet et al., 2010; Rixon et al., 2011; Dubernet et al., 2016; Albert et al., 2020).

\section{REFERENCES}

Adelman, S. J., Bidelman, W. P. \& Pyper, D. M. 1979. The peculiar A star gamma Equulei: a line identification study of lambda lambda 3086 - 3807. Astrophys. J. Suppl., 40, pp. 371-424. DOI: $10.1086 / 190592$

Albert, D., Antony, B., Ba, Y. A., Babikov, Y.L., Bollard, P., Boudon, V., Delahaye, F., Del Zanna, G., Dimitrijević, M. S. et al. 2020. A decade with VAMDC: results and ambitions. Atoms, 8(4), pp. 76. https://doi.org/10.3390/atoms8040076

Allen, D. M. \& Porto de Mello, G. F. 2007. Ruthenium and hafnium abundances in giant and dwarf barium stars. Astron. Astophys., 474, pp. 221-228. https://doi.org/10.1051/00046361:20066735

Beauchamp, A., Wesemael, F. \& Bergeron, P. 1997. Spectroscopic Studies of DB White Dwarfs: Improved Stark Profiles for Optical Transitions of Neutral Helium. Astrophys. J. Suppl., 108, pp. 559-573. https://doi.org/10.1086/312961

Biémont, E., Grevesse, N., Kwiatkovski, M., \& Zimmermann, P. 1984. Lifetime measurements for Ru I and the solar abundance of ruthenium. Astron. Astrophys, 131, pp. 364-366.

Dimitrijević, M. S. 2017. Stark widths of Sc IV spectral lines within $4 \mathrm{~s}-4 \mathrm{p}$ transition array. The University Thought - Publication in Natural Sciences, 7(2), pp. 76-80. https://doi.org/10.5937/univtho7-15815

Dimitrijević, M. S. 2020. Stark broadening of Os II spectral lines. The University Thought - Publication in Natural Sciences, 10(2), pp. 65-70. https://doi.org/10.5937/bnsr10-27823

Dimitrijević, M. S. \& Konjević, N. 1980. Stark widths of doublyand triply-ionized atom lines. J. Quant. Spectrosc. Radiative Transfer, 24, pp. 451-459. https://doi.org/10.1016/00224073(80)90014-X

Dimitrijević, M. S. \& Konjević, N. 1987. Simple estimates for Stark broadening of ion lines in stellar plasma. Astron. Astrophys., 172, pp. 345-349.

Dimitrijević, M. S. \& Kršljanin, V. 1986. Electron-impact shifts of ion lines - Modified semiempirical approach. Astron. Astrophys., 165, pp. 269-274.
Dimitrijević, M. S., \& Popović, L. Č. 2001. Modified Semiempirical Method. J. Appl. Spectrosc., 68, pp. 893-901. https://doi.org/10.1023/A:1014396826047

Dimitrijević, M. S. \& Sahal-Bréchot, S. 2014, On the Application of Stark Broadening Data Determined with a Semiclassical Perturbation Approach. Atoms, 2(3), pp. 357-377. https://doi.org/10.3390/atoms2030357

Dubernet, M. L., Antony, B. K., Ba, Y. A., Babikov, Yu. L., Bartschat, K., Boudon, V. et al. 2016. The virtual atomic and molecular data centre (VAMDC) consortium. J. Phys. B, 49(7), 074003. https://doi.org/10.1088/0953-4075/49/7/074003

Dubernet, M. L., Boudon, V., Culhane, J. L., Dimitrijević, M. S., Fazliev, A. Z., Joblin, C. et al. 2010. Virtual atomic and molecular data centre. J. Quant. Spectrosc. Radiative Transfer, 111(15), pp. 2151-2159. https://doi.org/10.1016/j.jqsrt.2010.05.004

Griem, H. R. 1974. Spectral line broadening by plasmas (New York.: Academic Press, Inc.)

Hansen, C. J., Andersen, \& Christlieb, A. C. 2014. Stellar abundances and presolar grains trace the nucleosynthetic origin of molybdenum and ruthenium. Astron. Astrophys., 568, A47. DOI: 10.1051/0004-6361/201423535

Kramida, A., Ralchenko, Yu., Reader, J. \& -NIST ASD Team 2020. NIST Atomic Spectra Database. Gaithersburg, MD: National Institute of Standards and Technology. (ver. 5.5.1), Retrived from https://physics.nist.gov/asd, 2020, $15^{\text {th }}$ of September.

Merril, P. W. 1947. Atomic lines in the spectrum of R Andromedae. Astrophys. J., 105, pp. 360-375.

Milovanović, N., Dimitrijević, M. S., Popović, L. Č. \& Simić, Z. 2004. Importance of collisions with charged particles for stellar UV line shapes: Cd III, Astron. Astrophys., 417, pp. 375-380. https://doi.org/10.1051/0004-6361:20034162

Mishenina, T., Pignatari, M., Gorbaneva, T., Travaglio, C., Côté, B., Thielemann, F.-K. \& Soubiran, C. 2019.Enrichment of the Galactic disc with neutron-capture elements: Mo and Ru. Monthly Notices Roy. Astron. Soc., 489, pp. 1697-1708. DOI: 10.1093/mnras/stz2202

Moore, C. E. 1971. Atomic Energy Levels as Derived from the Analysis of Optical Spectra - Molybdenum through Lanthanum and Hafnium through Actinium. Nat. Stand. Ref. Data Ser. 35, Vol. III. Washington: Nat. Bur. Stand. US, pp. 1-245.

Rixon, G., Dubernet, M. L., Piskunov, N., Walton, N., Mason, N., Le Sidaner, P., et al.2011. VAMDC-The Virtual Atomic and Molecular Data Centre-A New Way to Disseminate Atomic and Molecular Data-VAMDC Level 1 Release. AIP Conf. Proc., 1344, pp. 107-115. https://doi.org/10.1063/1.3585810

Roederer, I. U., Sneden, C., Lawler, J. E. \& Cowan, J. J. 2010. New abundance determinations of cadmium, lutetium, and osmiumin the r-procss enriched star BD +17 3248. Astrophys. J. Lett., 714, pp. L123-L127. https://doi.org/10.1088/20418205/714/1/L123

Sahal-Bréchot, S. 1969a. Impact theory of the broadening and shift of spectral lines due to electrons and ions in a plasma. Astron. Astrophys., 1, pp. 91-123. 
Sahal-Bréchot, S. 1969b. Impact theory of the broadening and shift of spectral lines due to electrons and ions in a plasma (continued). Astron. Astrophys., 2, pp. 322-354.

Sahal-Bréchot, S., Dimitrijević, M. S. \& Ben Nessib, N. 2014. Widths and Shifts of Isolated Lines of Neutral and Ionized Atoms Perturbed by Collisions With Electrons and Ions: An Outline of the Semiclassical Perturbation (SCP) Method and of the Approximations Used for the Calculations. Atoms, 2, pp. 225-252. DOI: 10.3390/atoms2020225

Sahal-Bréchot, S., Dimitrijević, M. S. \& Moreau, N. 2020. Observatory of Paris / LERMA and Astronomical Observatory of Belgrade. Retrieved from http://starkb. obspm.fr, 2020 September $15^{\text {th }}$. PHYSICS

Sahal-Bréchot, S., Dimitrijević, M. S., Moreau, N. \& Ben Nessib, N. 2015. The STARK-B database VAMDC node: a repository for spectral line broadening and shifts due to collisions with charged particles. Physica Scripta, 90(5), 054008. https://doi.org/10.1088/0031-8949/90/5/054008

Simić, Z., Dimitrijević, M. S. \& Kovačević, A. 2009. Stark broadening of spectral lines in chemically peculiar stars: Te I lines and recent calculations for trace elements. New Astron. Rev., 53(710), pp. 246-251. https://doi.org/10.1016/j.newar.2009.08.005

Simić, Z., Dimitrijević, M. S., Milovanović, N. \& Sahal-Bréchot, S. 2005a. Stark broadening of Cd I spectral lines. Astron.
Astrophys., 441(1), pp. 391-393. https://doi.org/10.1051/00046361:20052701

Simić, Z., Dimitrijević, M. S., Popović, L. Č. \& Dačić, M. 2005b. Stark Broadening of F III Lines in Laboratory and Stellar Plasma. J. Appl. Spectrosc., 72(3), pp. 443-446. https://doi.org/10.1007/s10812-005-0095-4

Simić, Z., Dimitrijević, M. S., Popović, L. Č. \& Dačić, M. 2006. Stark broadening parameters for Cu III, Zn III and Se III lines in laboratory and stellar plasma. New Astron. 12(3), pp. 187-191. https://doi.org/10.1016/j.newast.2006.09.001

Tankosić, D., Popović, L. Č. \& Dimitrijević, M. S. 2003. The electron-impact broadening parameters for Co III spectral lines. Astron. Astrophys., 399(2), pp. 795-797. https://doi.org/10.1051/0004-6361:20021801

Wiese, W. L. \& Konjević, N. 1982. Regularities and similarities in plasma broadened spectral line widths (Stark widths). J. Quant. Spectrosc. Radiative Transfer, 28(3), pp. 185-198. https://doi.org/10.1016/0022-4073(82)90022-X

Wiese, W. L. \& Konjević, N. 1992.Regularities in experimental Stark shifts. J. Quant. Spectrosc. Radiative Transfer, 47(3), pp. 185-200. https://doi.org/10.1016/0022-4073(92)90028-3 